\title{
Comparison of Markers of Coagulation Activation in Patients Under Oral Anticoagulation at Different Levels
}

\author{
By J. W. J. van Wersch ${ }^{1}$, C. H. van Mourik-Alderliesten ${ }^{2}$ and A. Coremans ${ }^{3}$ \\ ${ }^{1}$ Haematological Laboratory \\ 2 Thrombosis Center Eastern South-Limburg \\ ${ }^{3}$ Department of Internal Medicine \\ De Wever Ziekenhuis, Heerlen, The Netherlands
}

(Received February 14/April 21, 1992)

Summary: Three groups of patients receiving oral anticoagulation treatment were evaluated. The groups consisted of patients with mechanical heart valve prosthesis $(n=60)$, patients after coronary bypass graft surgery $(n=60)$ and patients using oral anticoagulation after deep venous thrombosis or pulmonary embolism $(\mathrm{n}=60)$.

The patient groups were subdivided into three groups of 20 patients, each group receiving different levels of oral anticoagulation as indicated by the international normalized ratio (INR). Prothrombin fragment $1+2$, thrombin-antithrombin III complexes and fibrin monomers were determined as coagulation activation makers. The prothrombin fragments $1+2$ were INR dependent in all groups whereas the thrombin-antithrombin III values were only INR dependent in the group of patients with mechanical heart valve prosthesis. For fibrin monomers no correlation with the INR levels could be found.

These results indicate that prothrombin fragment $1+2$ is the only laboratory quantity of the three, which provides a suitable index of low thrombin activity during anticoagulation therapy.

\section{Introduction}

There is wide acceptance that oral anticoagulants are effective in the primary and secondary prevention of thromboembolic complications after deep venous thrombosis (1), in patients with mechanical or biological heart valve prosthesis $(2,3)$, after myocardial infarction (4), in the prevention of stroke (5) and after major orthopaedic surgery (6). The intensity of oral anticoagulation however has been matter of discussion for a long time $(7,8)$. High-intensity anticoagulation (INR 3.0-4.0) enhances the risk of minor or major bleeding complications. Moderate-intensity anticoagulation (INR 2.0-2.5), however, may be equally effective, as indicated in several clinical trials in patients with bioprosthesis of the heart valve (2) or after deep venous thrombosis (9), and might lower the risk of major haemorrhage (10). From the laboratory point of view, the final aim of oral anticoagulation is the reduction of thrombin generation to such a level that fibrin can no longer be formed in harmful quantities.

Several tests for the activation extent of the haemostatic system are now available, such as the measurement of fibrinopeptide A, thrombin-antithrombin III complex (11), fibrin monomer as well as prothrombin fragment $1+2$. The levels of both fibrinopeptide $A$ $(12,13)$ and prothrombin fragment $1+2(14)$ have been shown to be dependent on the degree of anticoagulation.

A scheme of the relevant part of the coagulation and fibrinolysis cascade is shown in figure 1. 

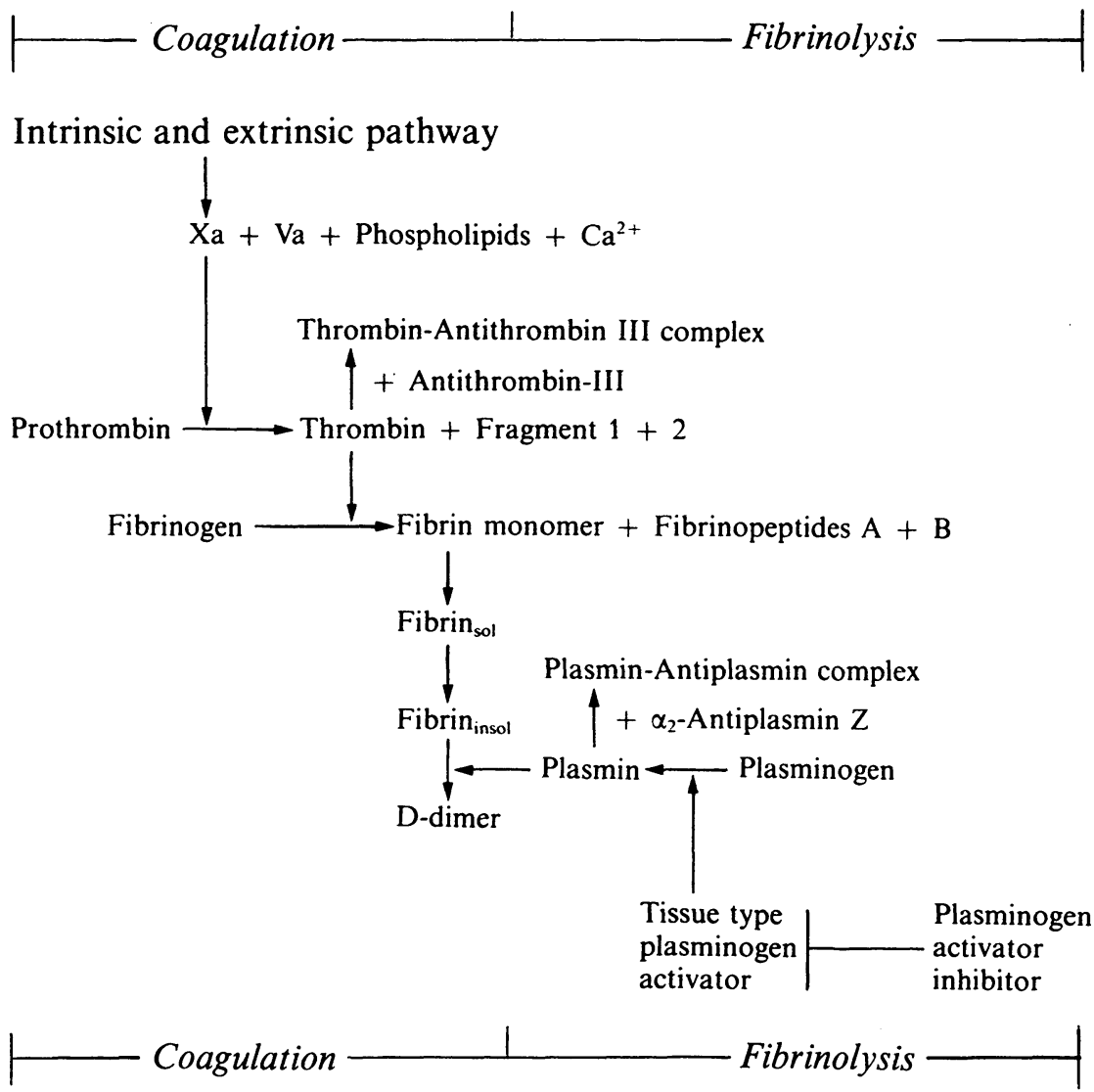

Fig. 1. Scheme of the relevant part of the coagulation and fibrinolysis cascade.

The aim of this study was to establish the extent of prothrombin activation and its effect on thrombin activity in several patient groups receiving different degrees of oral anticoagulation treatment, and to compare the measured quantities (i.e. thrombin-antithrombin III, fibrin monomer, prothrombin fragment $1+2$ ) with regard to their usefulness as an index of thrombin activity during oral anticoagulation.

\section{Materials and Methods}

Methods

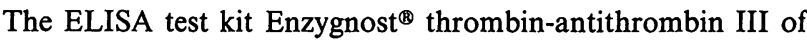
Behring Corp. (Marburg, Germany) was used for thrombinantithrombin III measurements. Prothrombin fragment $1+2$ was determined with the Enzygnost ${ }^{\circledR} \mathrm{F} 1+2$ of Behring Corp. (Marburg, Germany). Fibrin monomers were measured with the chromogenic Coa set test of Kabi Vitrum Diagnostica (Mölndal, Sweden). Prothrombin times were assessed with the Chromoquick ${ }^{\circledR}$ reagent of Behring Corp. (Marburg, Germany) on a Cobas Bio (Hoffmann-La Roche, Grenzach-Wyhlen, Switzerland) and were reported as INR-values.

\section{Patients}

Three groups of patients were evaluated. All patients were monitored routinely for the efficiency of oral anticoagulation treatment.
Group 1 consisted of 60 patients with (mechanical) heart valve prosthesis.

Group 2 contained 60 patients after coronary artery bypass graft surgery.

Group 3 was composed of 60 patients using oral anticoagulation after deep venous thrombosis or pulmonary embolism.

Group 1 and 3 were subdivided into anticoagulation levels INR 3.6-4.8, INR 2.5-3.5 and INR 2.1-2.4. Group 2 was subdivided into INR 2.9-4.8, INR $2.1-2.8$ and INR 1.8-2.0. The levels of each group were determined according to the recommendations for optimal anticoagulation of the Federation of Dutch Thrombosis Centers (15). All patients were under stable oral anticoagulation and were attributed to one of the categories on the basis of their actual INR values. The reference values were obtained from 50 age and sex matched healthy individuals.

\section{Samples}

Blood was collected between 9 and $11 \mathrm{a} . \mathrm{m}$. in trisodium citrate (0.11 mol/l)-containing plastic tubes $(9: 1$ by vol.). After centrifugation $(1600 \mathrm{~g}, 20 \mathrm{~min}$, room temperature) the plasma was collected, analysed for the prothrombin time and after that immediately deep frozen at $-70^{\circ} \mathrm{C}$ until batch analysis of the specimens for the other analytes was performed. Before analysis they were thawed with tap water for $5 \mathrm{~min}$ just before use.

\section{Results}

In table 1 the medians and interquartile ranges of the investigated quantities are given for the group of healthy individuals. 
Tab. 1. Medians, interquartile ranges and reference ranges for the different parameters in healthy individuals.

\begin{tabular}{llll}
\hline Quantity & \multicolumn{2}{l}{ Group of healthy individuals $(\mathrm{N}=50)$} \\
\cline { 2 - 4 } & Median & Interquartile range & Reference range \\
\hline Prothrombin fragment 1 $+2(\mathrm{nmol} / \mathrm{l})$ & 0.66 & 0.26 & $0.44-1.11$ \\
Thrombin-antithrombin III $(\mu \mathrm{g} / \mathrm{l})$ & 2.4 & 1.4 & $1.0-4.1$ \\
Fibrin monomers $(\mathrm{nmol} / \mathrm{l})$ & 10.5 & 2.0 & $8.4-13.2$ \\
\hline
\end{tabular}

In table 2 the Spearman rank coefficients of correlation are given between INR and prothrombin fragment $1+2$, thrombin-antithrombin III and fibrin monomers in the different patient groups. Only prothrombin fragment $1+2$ concentrations showed significant correlations with INR in all patient groups.

A thrombin-antithrombin III correlation with INR only was obtained in the group with mechanical heart valve prosthesis $(r=-0.36, p=0.004)$.

Table 3 shows the results of the comparison of the different quantities in the group of patients with mechanical heart valve prosthesis according to their INR category:

a significant increase was found for prothrombin fragment $1+2$; thrombin-antithrombin III values were significantly different between categories $\mathrm{INR}_{3}$ and $\mathrm{INR}_{1}$, and between $\mathrm{INR}_{3}$ and $\mathrm{INR}_{2}$; fibrin monomers showed a significant difference only between $\mathrm{INR}_{3}$ and $\mathrm{INR}_{2}$.
The comparison of the investigated quantities in the group of patients with coronary artery bypass grafts in the different INR groups is given in table 4; prothrombin fragment $1+2$ was the only variable with significant alterations: $\mathrm{INR}_{2}$ vs $\mathrm{INR}_{1} \mathrm{p}<0.005, \mathrm{INR}_{3}$ vs $I_{N R} p<0.001$. Table 5 contains the results of the comparison of the deep venous thrombosis and pulmonary embolism patient groups; significant prothrombin fragment $1+2$ differences were obtained between $\mathrm{INR}_{2}$ and $\mathrm{INR}_{1}(\mathrm{p}<0.03), \mathrm{INR}_{3}$ and $\mathrm{INR}_{2}$ $(p<0.01)$, and between $\operatorname{INR}_{3}$ and $\operatorname{INR}_{1}(\mathrm{p}<0.001)$.

\section{Discussion}

The intensity of oral anticoagulation has long been matter of discussion, and the problem always has been approached from a clinical standpoint. It is common opinion that the ultimate goal of treatment with oral anticoagulation is the prevention of thrombin formation or the reduction thereof to a level where

Tab. 2. Spearman rank correlation (p-values) between INR levels and prothrombin fragment $1+2$, thrombin-antithrombin III and fibrin monomer.

\begin{tabular}{|c|c|c|c|c|c|c|}
\hline \multirow[b]{3}{*}{ Group $1(\mathrm{n}=60)$} & \multicolumn{6}{|c|}{ Spearman rank correlation ( $\mathrm{p}$-values) between INR and } \\
\hline & \multicolumn{2}{|c|}{ Prothrombin fragment $1+2$} & \multicolumn{2}{|c|}{ Thrombin-antithrombin III } & \multicolumn{2}{|c|}{ Fibrin monomer } \\
\hline & -0.56 & $(<0.0001)$ & -0.36 & $(0.004)$ & -0.06 & $(0.65)$ \\
\hline Group $2(n=60)$ & -0.47 & $(0.0002)$ & 0.09 & $(0.48)$ & 0.09 & $(0.47)$ \\
\hline Group $3(n=60)$ & -0.50 & $(<0.0001)$ & -0.11 & $(0.36)$ & -0.15 & $(0.23)$ \\
\hline
\end{tabular}

Group 1 = patients with mechanical heart valve prosthesis

Group 2 = patients with coronary artery bypass grafts

Group 3 = patients after deep venous thrombosis or pulmonary embolism

Tab. 3. Comparison of the medians and interquartile ranges (IR) of the investigated quantities in the group of patients with mechanical heart valve prosthesis according to the INR categories. The significances were calculated with the MannWhitney-Wilcoxon test. Each INR subgroup consisted of 20 patients.

\begin{tabular}{|c|c|c|c|c|c|c|}
\hline \multirow[t]{2}{*}{ Quantity } & \multirow{2}{*}{$\begin{array}{l}\text { INR1 } \\
(4.8-3.6) \\
\text { Median } \\
\text { (IR) }\end{array}$} & \multirow{2}{*}{$\begin{array}{l}\text { INR2 } \\
(3.5-2.5) \\
\text { Median } \\
\text { (IR) }\end{array}$} & \multirow{2}{*}{$\begin{array}{l}\text { INR3 } \\
(2.4-2.1) \\
\text { Median } \\
\text { (IR) }\end{array}$} & \multicolumn{3}{|c|}{ Significances P-values } \\
\hline & & & & 2 vs 1 & 3 vs 2 & 3 vs 1 \\
\hline Prothrombin fragment $1+2(\mathrm{nmol} / \mathrm{l})$ & $\begin{array}{c}0.12 \\
(0.08)\end{array}$ & $\begin{array}{c}0.15 \\
(0.09)\end{array}$ & $\begin{array}{c}0.25 \\
(0.18)\end{array}$ & $<0.03$ & $<0.0001$ & $<0.001$ \\
\hline Thrombin-antithrombin III $(\mu \mathrm{g} / \mathrm{l})$ & $\begin{array}{c}1.5 \\
(0.4)\end{array}$ & $\begin{array}{c}1.6 \\
(0.5)\end{array}$ & $\begin{array}{c}2.0 \\
(0.8)\end{array}$ & N.S. & $<0.005$ & $<0.005$ \\
\hline Fibrin monomer (nmol/l) & $\begin{array}{c}16.8 \\
(4.7)\end{array}$ & $\begin{array}{c}14.4 \\
(3.3)\end{array}$ & $\begin{array}{c}17.6 \\
(8.3)\end{array}$ & N.S. & $<0.02$ & N.S. \\
\hline
\end{tabular}


Tab. 4. Comparison of the medians and interquartile ranges (IR) of the investigated quantities in the group of patients with coronary artery bypass grafts according to the INR categories. The significances were calculated with the Mann-WhitneyWilcoxon test. Each INR subgroup consisted of 20 patients.

\begin{tabular}{|c|c|c|c|c|c|c|}
\hline \multirow[t]{2}{*}{ Quantity } & \multirow{2}{*}{$\begin{array}{l}\text { INR1 } \\
(4.8-2.9) \\
\text { Median } \\
\text { (IR) }\end{array}$} & \multirow{2}{*}{$\begin{array}{l}\text { INR2 } \\
(2.8-2.1) \\
\text { Median } \\
\text { (IR) }\end{array}$} & \multirow{2}{*}{$\begin{array}{l}\text { INR3 } \\
(2.0-1.8) \\
\text { Median } \\
\text { (IR) }\end{array}$} & \multicolumn{3}{|c|}{ Significances P-values } \\
\hline & & & & 2 vs 1 & 3 vs 2 & 3 vs 1 \\
\hline Prothrombin fragment $1+2(\mathrm{nmol} / \mathrm{l})$ & $\begin{array}{c}0.20 \\
(0.11)\end{array}$ & $\begin{array}{c}0.27 \\
(0.21)\end{array}$ & $\begin{array}{c}0.32 \\
(0.15)\end{array}$ & $<0.005$ & N.S. & $<0.001$ \\
\hline Thrombin-antithrombin III $(\mu \mathrm{g} / \mathrm{l})$ & $\begin{array}{c}1.7 \\
(0.6)\end{array}$ & $\begin{array}{c}1.9 \\
(0.9)\end{array}$ & $\begin{array}{c}1.7 \\
(0.6)\end{array}$ & N.S. & N.S. & N.S. \\
\hline Fibrin monomer (nmol/l) & $\begin{array}{c}19.1 \\
(6.0)\end{array}$ & $\begin{array}{c}17.8 \\
(7.1)\end{array}$ & $\begin{array}{c}17.3 \\
(8.6)\end{array}$ & N.S. & N.S. & N.S. \\
\hline
\end{tabular}

Tab. 5. Comparison of the medians and interquartile ranges (IR) of the investigated quantities in the group of patients with prophylactical treatment after deep venous thrombosis or pulmonary embolism according to the INR categories. The significances were calculated with the Mann-Whitney-Wilcoxon test. Each INR subgroup consisted of 20 patients.

\begin{tabular}{|c|c|c|c|c|c|c|}
\hline \multirow[t]{2}{*}{ Quantity } & \multirow{2}{*}{$\begin{array}{l}\text { INR1 } \\
(4.8-3.6) \\
\text { Median } \\
\text { (IR) }\end{array}$} & \multirow{2}{*}{$\begin{array}{l}\text { INR2 } \\
(3.5-2.5) \\
\text { Median } \\
\text { (IR) }\end{array}$} & \multirow{2}{*}{$\begin{array}{l}\text { INR3 } \\
(2.4-2.1) \\
\text { Median } \\
\text { (IR) }\end{array}$} & \multicolumn{3}{|c|}{ Significances P-values } \\
\hline & & & & 2 vs 2 & 3 vs 2 & 3 vs 1 \\
\hline Prothrombin fragment $1+2(\mathrm{nmol} / \mathrm{l})$ & $\begin{array}{c}0.15 \\
(0.06)\end{array}$ & $\begin{array}{c}0.17 \\
(0.07)\end{array}$ & $\begin{array}{c}0.23 \\
(0.16)\end{array}$ & $<0.03$ & $<0.01$ & $<0.001$ \\
\hline Thrombin-antithrombin III $(\mu \mathrm{g} / \mathrm{l})$ & $\begin{array}{c}1.4 \\
(0.3)\end{array}$ & $\begin{array}{c}1.4 \\
(0.3)\end{array}$ & $\begin{array}{c}1.4 \\
(0.6)\end{array}$ & N.S. & N.S. & N.S. \\
\hline Fibrin monomer (nmol/l) & $\begin{array}{c}16.7 \\
(9.2)\end{array}$ & $\begin{array}{c}16.8 \\
(8.1)\end{array}$ & $\begin{array}{c}20.4 \\
(5.3)\end{array}$ & N.S. & $<0.02$ & N.S. \\
\hline
\end{tabular}

Tab. 6. Comparison of the medians and interquartile ranges (IR) of the investigated quantities in the group of patients with prophylactical treatment after total hip or knee arthroplasty according to the INR categories. The significances were calculated with the Mann-Whitney-Wilcoxon test. Each INR subgroup consisted of 20 patients.

\begin{tabular}{|c|c|c|c|}
\hline \multirow[t]{2}{*}{ Quantity } & \multirow{2}{*}{$\begin{array}{l}\text { INR2 } \\
(3.5-2.5) \\
\text { Median } \\
\text { (IR) }\end{array}$} & \multirow{2}{*}{$\begin{array}{l}\text { INR3 } \\
(2.4-2.1) \\
\text { Median } \\
\text { (IR) }\end{array}$} & \multirow{2}{*}{$\begin{array}{l}\text { Significance } \\
\text { P-value }\end{array}$} \\
\hline & & & \\
\hline Prothrombin fragment $1+2(\mathrm{nmol} / \mathrm{l})$ & $\begin{array}{c}0.29 \\
(0.13)\end{array}$ & $\begin{array}{c}0.30 \\
(0.13)\end{array}$ & N.S. \\
\hline Thrombin-antithrombin III $(\mu \mathrm{g} / \mathrm{l})$ & $\begin{array}{c}1.9 \\
(0.4)\end{array}$ & $\begin{array}{c}1.7 \\
(0.9)\end{array}$ & N.S. \\
\hline Fibrin monomer (nmol/1) & $\begin{array}{c}14.9 \\
(4.8)\end{array}$ & $\begin{array}{c}18.7 \\
(2.9)\end{array}$ & N.S. \\
\hline
\end{tabular}

no or nearly no thrombin generation occurs. Up to now the decreased activity of the coagulation system during anticoagulation treatment has been determined by measuring the prothrombin time as a global test for the extrinsic coagulation pathway. We have now used the relatively new assays for prothrombin fragment $1+2$, thrombin-antithrombin III and fibrin monomer and tested them for their usefulness as markers of the effect of prothrombin activation and of thrombin activity during oral anticoagulation. Cor- relation studies between these coagulation activation markers and the INR show that only prothrombin fragment $1+2$ decreases in all patient groups with the increase of the INR. Thrombin-antithrombin III decreased only in the group with mechanical heart valve prosthesis. The fibrin monomer concentrations showed no correlation in any patient group. Thus, prothrombin fragment $1+2$ seems to be suited for the monitoring of the reduction of thrombin formation in patients under oral anticoagulation treatment. 
The results in the patient group with mechanical heart valve prosthesis showed significantly decreased values for prothrombin fragment $1+2$ and low normal thrombin-antithrombin III concentrations with increasing INR values. The actual median concentrations of prothrombin fragment $1+2$ are located significantly below those of the lower limit of the reference group. Thus, thrombin formation is depressed to such a low level that from the laboratory point of view a prolonged period in the lowest INR category should not be a cause of concern in this patient group.

In the group of patients with coronary artery bypass grafts, only prothrombin fragment $1+2$ values showed a decrease with increasing INR values. The median values of the different anticoagulation intensities are below the lower limit of the reference group and are somewhat higher than those in the group of patients with mechanical heart valve prosthesis. The prothrombin fragment $1+2$ levels are also low in the group of patients receiving prophylactical treatment with oral anticoagulants after deep venous thrombosis and pulmonary embolism, and they also decrease with increasing INR. The question is whether the differences between the median values for prothrombin fragment $1+2$ in the different intensity categories are an adequate index of the decrease of the thrombin. Considering the effect of oral anticoagulation in the three patient groups on the concentrations of prothrombin fragment $1+2$, thrombin-antithrombin III and fibrin monomer, it appears that prothrombin fragment $1+2$ is the most suitable for the measurement of the effect of oral anticoagulation. The test allows reliable measurements below the lower limit of the reference range; this is of interest especially in this study, which includes properly anticoagulated patients. On the basis of the concentrations measured for prothrombin fragment $1+2$ it is clear that under stable anticoagulation the resulting thrombin activity is most depressed in the mechanical heart valve prosthesis and the deep venous thrombosis/pulmonary embolism group, followed by the coronary artery bypass graft group, but it is probably adequate in all groups. The thrombin-antithrombin III concentrations in the various patient groups and the different intensity categories of oral anticoagulation are less informative, although the median values are mostly in the lower quartile of the reference range. The fibrin monomer values are useless for the evaluation of the reduced thrombin activity under oral anticoagulation. The median values are even higher in the patient groups than in the reference groups. The explanation for this is unclear, but there might be some interference in the test system. It is, however, also conceivable that the enhancement of the tissue plasminogen activator concentrations in anticoagulated patients, as we reported in a recent study (16), also plays a role. Elevated tissue plasminogen activator concentrations could produce additional plasmin in the test system, which in turn would cause higher fibrin monomer values than expected.

In conclusion, from the three markers of coagulation activation used in this study, only the prothrombin fragment $1+2$ concentrations showed full inverse parallelism with the INR levels. This has also been reported recently by Mannucci (17). The median prothrombin fragment $1+2$ concentrations were strongly reduced in all patient groups, indicating satisfactory decrease of coagulation by oral anticoagulation treatment. The measurement of prothrombin fragment $1+2$ seems to be appropriate in selected cases as an additional value for adjusting and monitoring the efficacy of anticoagulant therapy. This is important, because in general the question is whether the high intensities of oral anticoagulation are necessary for all indications as commonly recommended. In several clinical studies less intense oral anticoagulation $(2,3,5,9,18-20)$ and other therapeutic regimens $(1,21-26)$ have already been tested for the different indications of oral anticoagulation. Measurement of prothrombin fragment $1+2$ might therefore be helpful in future clinical studies dealing with the efficacy of oral anticoagulation.

\section{References}

1. Taberner, D. A., Poller, L., Burslem, R. W. \& Jones, J. B. (1987) Oral anticoagulants controlled by the British comparative thromboplastin versus low-dose heparin in prophylaxis of deep vein thrombosis. Brit. Med. 7, 272-274.

2. Turpie, A. G., Hirsch, J., Gunstensen, J., Nelson, H. \& Gent, M. (1988) Randomized comparison of two intensities of oral anticoagulation therapy after tissue valve replacement. Lancet $i, 1242-1245$.

3. Saour, J. N., Sieck, J. O., Mamo, L. A. R. \& Gallus, A. S. (1990) Trial of different intensities of anticoagulation in patients with prosthetic heart valves. N. Engl. J. Med. 322, $428-432$.

4. Smith, P., Arnesen, H. \& Holme, I. (1990) The effect of warfarin on mortality and reinfarction after myocardial infarction. N. Engl. J. Med. 323, 137-152.

5. The Boston Area Anticoagulation Trial for Atrial Fibrillation Investigators. The effect of low-dose warfarin on the risk of stroke in patients with non-rheumatic atrial fibrillation (1990) N. Engl. J. Med. 323, 1505-1511.

6. Leyvraz, R., Richard, J., Bachmann, F., van Melle, C., Treyvand, J. M., Livio, J. J. \& Candardjis, G. (1983) Adjusted versus fixed-dose subcutaneous heparin in the prevention of deep venous thrombosis after total hip replacement. N. Engl. J. Med. 309, 954-958. 
7. Hirsch, J., Poller, L., Deykin, D., Levine, M. \& Dalen, J. E. (1989) Optimal therapeutic range for oral anticoagulation. Chest 95, 5-11.

8. Loeliger, E. A. \& Broekmans, A. W. (1985) Optimal therapeutic anticoagulation. Haemostasis 15, 283-292.

9. Hull, R., Hirsh, J., Jay, R., Carter, C., England, C., Gent, M., Turpie, A. G., McLoughlin, D., Dodd, P., Thomas, M., Raskob, G. \& Ockelford, P. (1982) Different intensities of oral anticoagulant therapy in the treatment of proximal vein thrombosis. N. Engl. J. Med. 307, 1676-1681.

10. Wintzen, A. R., Tijssen, J. G., de Vries, W. A., Loeliger, E. A. \& Roos, J. (1982) Risks of long-term oral anticoagulant therapy in elderly patients after myocardial infarction. Second report of the Sixty Plus Reinfarction Study Research Group. Lancet $i, 64-68$.

11. Pelzer, H., Schwarz, A. \& Heimburger, N. (1988) Determination of human thrombin-antithrombin III complex in plasma with an enzyme linked immuno sorbent assay. Thromb. Haem. 59, $101-106$.

12. Marongiu, F., Sorano, G. G., Mameli, G., Mamusa, A. M., Cambuli, A. B., Conti, M., Sanna, M. P., Farci, P. \& Balestrieri, A. (1989) Thrombin activity and oral anticoagulant therapy: a preliminary study. Haemostasis 19, $142-146$.

13. Marongiu, F., Sorano, G. G., Mameli, G., Mamusa, A. M., Cambuli, A. B., Conti, M., Cadoni, M. C. \& Balestrieri, A. (1990) Thrombin activity and oral anticoagulant therapy: after further evaluation. Haemostasis 20,63-64.

14. Bruhn, H. D., Pelzer, H. \& Wagner, C. (1991) Quantification of hypocoagulability induced by oral anticoagulant therapy by measurement of prothrombin fragment $\mathrm{F} 1+2$. Ann. Hematol. 62 A 67 (abstract).

15- Van den Besselaar, A. M. H. P., van der Meer, F. J. M. \& Gerrits-Drabbe, C. W. (1988) Therapeutic control of oral anticoagulant treatment in the Netherlands. Am. J. Clin. Pathol. 90, 685-690

16. Van Wersch, J. W. J. \& van Mourik-Alderliesten, C. H. (1992) Fibrinolysis and oral anticoagulation. Fibrinolysis (in press).

17, Mannucci, P. M., Bottasso, B., Tripodi, A. \& Bianchi Bonomi, A. (1991) Prothrombin fragment $1+2$ and intensity of treatment with oral anticoagulants. Thrombosis and Haemostasis 66, 741.
18. Altman, Rouvier, J., Gurfinkel, E., D’Ortencio, O., Manzanel, R., de La Fuente, L. \& Favaloro, R. G. (1991) Comparison of two levels of anticoagulant therapy in patients with substitute heart valves. J. Thorac. Cardiovasc. Surg. 101, 427-431.

19. Poller, L., McKernan, A., Thomson, J. M., Elstein, M., Hirsch, P. J. \& Jones, J. B. (1987) Fixed minidose warfarin: a new approach to prophylaxis against venous thrombosis after major surgery. Brit. Med. J. 295, 1309-1312.

20. Bern, M. M., Lokich, J. J., Wallach, S. R., Bothe, A. Jr., Benotti, P. N., Arkin, C. F., Greco, F. A., Huberman, M. \& Moore, C. (1990) Very low doses of warfarin can prevent thrombosis in central venous catheters. A randomized prospective trial. Ann. Intern. Med. 112, 423-428.

21. Powers, P. J., Gent, M., Jay, R. M., Julian, D. H., Turpie, A. G., Levine, M. \& Hirsh, J. (1989) A randomized trial of less intense postoperative warfarin or aspirin therapy in the prevention of venous thromboembolism after surgery for fractured hip. Arch. Intern. Med. 149, $771-774$.

22. Mok, C. K., Boey, J., Wang, R., Chan, T. K., Cheung, K. L., Lee, P. K., Chaw, J., Ng, R. P. \& Tse, T. F. (1985) Warfarin versus dipyridamole-aspirin and pentoxifyllineaspirin for the prevention of prosthetic heart valve thromboembolism: a prospective clinical trial. Circulation 72 , 1059-1063.

23. Hull, R., Delmore, T., Genton, E., Hirsh, J., Gent, M., Sackett, D., McLoughlin, D. \& Armstrong, P. (1979) Warfin sodium versus low-dosis heparin in the long-term treatment of venous thrombosis. N. Engl. J. Med. 301, 855-858.

24. Hull, R., Delmore, T., Carter, C., Hirsh, J., Genton, E., Gent, M., Turpie, G. \& McLoughlin, D. (1982) Adjusted subcutaneous heparin versus warfarin sodium in the longterm treatment of venous thrombosis. N. Engl. J. Med. $306,189-194$.

25. The EPSIM Research Group (1982) A controlled comparison of aspirin and oral anticoagulants in prevention of death after myocardial infarction. N. Engl. J. Med. 307, $701-708$.

26. Petersen, P., Boysen, G., Godtfredsen, J., Andersen, E. D. \& Andersen, B. (1989) Placebo-controlled, randomised trial of warfarin and aspirin for prevention of thromboembolic complications in chronic atrial fibrillation: the Copenhagen AFASAK study. Lancet $i, 175-179$.

Dr. J. W. J. van Wersch

Hoofd Haematologisch Lab.

De Wever Ziekenhuis

Henry Dunantstraat 5

NL-6419 PC Heerlen 